\title{
KALIBRASI MODEL SIMULASI VISSIM
}

\author{
DR. Effendhi Prih R,MT \\ Dosen STTD \\ J1. Raya Setu no.89 \\ Cibuntu - Cibitung \\ Tlp/Fax : ( 021 ) 8254640
}

\author{
DR.M. GunturMT \\ Dosen STTD \\ J1. Raya Setu no.89 \\ Cibuntu - Cibitung \\ Tlp/Fax : ( 021 ) 8254640
}

\author{
Dra. Siti Umiyati,MM \\ Dosen STTD \\ Jl. Raya Setu no.89 \\ Cibuntu - Cibitung \\ Tlp/Fax: ( 021 ) 8254640
}

\author{
Novita Sari,M.Eng \\ Dosen STTD \\ J1. Raya Setu no.89 \\ Cibuntu - Cibitung \\ Tlp/Fax : ( 021 ) 8254640 \\ Dessy Angga A,M.Sc \\ Dosen STTD \\ J1. Raya Setu no.89 \\ Cibuntu-Cibitung \\ Tlp/Fax : ( 021 ) 8254640
}

\author{
Dani Hardianto,M.Sc \\ Dosen STTD \\ J1. Raya Setu no.89 \\ Cibuntu - Cibitung \\ Tlp/Fax : ( 021 ) 8254640
}

\author{
Sabrina Handayani,MT \\ Dosen STTD \\ Jl. Raya Setu no.89 \\ Cibuntu - Cibitung \\ Tlp/Fax : ( 021 ) 8254640
}

\begin{abstract}
In analyzing the transportation of a road network, many encountered limitations and difficulties. A lot of time, effort and cost are used to analyze and know traffic performance. One of the software that can be used is the application PTV Vissim 9. Vissim model itself is basically given or there are arrangements that have been set by the creator with the characteristics of the country of origin, namely Germany and other developed countries where the country has different characteristics, seen from the traffic policy, arrangement, management and traffic engineering, modes of transportation and behavior of road users in which there are pedestrians and motorists. Vissim simulation model is a modeling with microscopic analysis in which formulate variables and algorithms related to Driving Behavior or road user behavior. It is intended to know indication of road user behavior toward traffic performance comprehensively but in micro scope.
\end{abstract}

Keyword: Traffic performance, Vissim simulation, microscopic analysis

\begin{abstract}
ABSTRAKSI
Dalam menganalisa transportasi suatu jaringan jalan, banyak ditemui keterbatasan dan kesulitan. Banyak waktu, tenaga dan biaya yang digunakan untuk menganalisa dan mengetahui kinerja lalu lintas. Salah satu perangkat lunak yang dapat digunakan adalah aplikasi PTV Vissim 9. Model Vissim itu sendiri pada dasarnya merupakan given atau terdapat pengaturan yang telah di atur oleh penciptanya dengan karakteristik negara asalnya, yakni negara Jerman dan negara maju lainnya dimana negara tersebut mempunyai karakteristik yang berbeda, dilihat dari kebijakan lalu lintas, pengaturan, manajemen dan rekayasa lalu lintas, moda transportasi dan perilaku pengguna jalan yang didalamnya terdapat pejalan kaki dan pengendara kendaraan. Model simulasi Vissim merupakan permodelan dengan analisa microscopis yang didalamnya merumuskan variabel dan alogaritma berkaitan dengan Driving Behaviour atau perilaku pengguna jalan. Hal ini dimaksudkan untuk mengetahui indikasi dari perilaku pengguna jalan terhadap kinerja lalu lintas secara komprehensif namun dalam lingkup mikro.
\end{abstract}

Keyword : Kinerja lalu lintas, simulasi Vissim, analisa microscopis 


\section{PENDAHULUAN}

\section{A. Latar Belakang Penelitian}

Transportasi merupakan suatu yang dinamis, dimana kondisinya akan senantiasa berubah mengikuti variable yang berkaitan sesuai dengan perubahan yang terjadi dari waktu ke waktu. Dalam menganalisa transportasi suatu jaringan jalan, banyak ditemui keterbatasan dan kesulitan. Banyak waktu, tenaga dan biaya yang digunakan untuk menganalisa dan mengetahui kinerja lalu lintas. Dalam hal ini untuk mempermudah analisa dalam suatu penelitian dari segi biaya, waktu dan tenaga dibutuhkan suatu alat bantu berupa aplikasi permodelan lalu lintas.. Salah satu perangkat lunak yang dapat digunakan adalah aplikasi PTV Vissim 9. Model Vissim itu sendiri pada dasarnya merupakan given atau terdapat pengaturan yang telah di atur oleh penciptanya dengan karakteristik negara asalnya, yakni negara Jerman

\section{Identifikasi Permasalahan}

Dari latar belakang di atas maka dapat diidentifikasi permasalahan sebagai berikut:

1. Belum terdapatnya alat bantu dalam analisa kinerja lalu lintas yang sesuai denga karakteristik wilayah studi. Sehingga dalam melakukan suatu penelitian dapat menghabiskan waktu, tenaga dan biaya banyak.

2. Hingga saat ini belum terdapat model simulasi Vissim 9 yang telah disesuaikan dengan karakteristik per wilayah studi, karena masih dalam setingan dasar yang merupakan implementasi dari karakteristik negara asalnya yakni Jerman, sehingga model simulasi Vissim 9 belum dapat digunakan untuk diterapkan dalam penelitian di Indonesia

3. Belum adanya kalibrasi model simulasi Vissim 9 yang sesuai dengan kondisi karakteristik Jaringan jalan di Indonesia yang di dalamnya terdiri dari kinerja ruas, simpang, jaringan jalan dan pejalan kaki yang telah disesuaikan dengan karakteristik lalu lintas di Indonesia.

\section{B. Rumusan Masalah}

Dengan melihat permasalahan di atas dan keterbatasan yang ada maka yang menjadi bahan penelitian ini adalah :

1. Bagaimana cara mengkalibrasi kinerja jaringan jalan menggunakan software Vissim 9 sesuai dengan karakteristik lalu lintas di Indonesia?

2. Apa saja variable yang digunakan di dalam permodelan Vissim 9 yang berpengaruh terhadap Nanalysis kinerja pada jaringan jalan, ruas jalan, kinerja persimpangan dan pejalan kaki? 


\section{Tujuan Penelitian}

Maksud dari penelitian ini adalah untuk melakukan kalibrasi model simulasi menggunakan Software Vissim 9, dalam rangka mendukung analisa dan penelitian lalu lintas agar lebih efektif dan efisien serta untuk medukung pengembangan pembelajaran.

Ada pun tujuan adalah :

1. Mengetahui tahapan kalibrasi model simulasi Vissim 9 terhadap karakteristik jaringan jalan Indonesia yang berkaitan dengan dengan kinerja ruas jalan, persimpangan dan karakterisitk pengguna jalan.

2. Mengetahui manfaat penggunaan software simulasi permodelan dalam rangka mendukung penelitian berkaitan analisa lalu lintas

\section{A. MODEL KALIBRASI VISSIM}

VISSIM adalah sebuah program simulasi mikroskopis yang digunakan untuk memodelkan arus lalu lintas multimoda. Menurut Aryandi (2014) melakukan penelitian menggunakan VISSIM dengan studi kasus di Simpang Mirota Kampus Terban Yogyakarta. Dengan menginput data geometrik simpang, volume lalu lintas dan waktu sinyal, dapat dihasilkan data output berupa panjang antrian. Hasil tersebut kemudian dijadikan sebagai parameter dalam pengkalibrasian. Panjang antrian maksimum, minimum dan rata-rata hasil dari pemodelan dibandingkan dengan hasil dari pengamatan langsung di lapangan. Setelah tahap kalibrasi dan validasi, dapat disimpulkan bahwa tidak ada perbedaan yang signifikan antara simulasi dengan hasil di lapangan, namun terdapat perbedaan yang cukup signifikan pada deviasi (penyebaran) hasil antrian.

\section{B. KALIBRASI DAN VALIDASI}

Menurut (Zudhy dan Nurjanah, 2015)Kalibrasi pada VISSIM merupakan proses dalam membentuk nilai-nilai parameter yang sesuai sehingga model dapat mereplikasi lalu lintas hingga kondisi yang semirip mungkin. Proses kalibrasi dapat dilakukan berdasarkan perilaku pengemudi daerah yang diamati. Metode yang digunakan adalah trial and error dengan mengacu pada penelitianpenelitian sebelumnya mengenai kalibrasi dan validasi menggunakan VISSIM.

GEH merupakan rumus statistik modifikasi dari Chi-squared dengan menggabungkan perbedaan antara nilai relatif dan mutlak. Rumus $G E H$ berikut ini memiliki ketentuan khusus dari nilai error yang dihasilkan seperti pada Tabel 1. Sedangkan rumus $M A P E$ yang juga dikenal sebagai rata-rata deviasi persentase absolut tersebut adalah persentase perbedaan antara data yang sebenarnya dengan data perkiraan. 
$G E H=\sqrt{\frac{\left(q_{\text {simulated }}-q_{\text {observed }}\right)^{2}}{0,5 \times\left(q_{\text {simulated }}+q_{\text {observed }}\right)}}$

dengan:

$q \quad=$ data volume arus lalu lintas (kendaraan/jam)

Tabel 1 Kesimpulan dari Hasil Perhitungan Rumus Statistik Geoffrey E. Havers

GEH $<5,0 \quad$ diterima

$5,0 \leq \mathrm{GEH} \leq 10,0$ peringatan: kemungkinan model eror atau data buruk

GEH > 10,0 ditolak

$M A P E=\frac{1}{n} \sum_{t=1}^{n}\left|\frac{A_{t}-F_{t}}{A_{t}}\right| \times 100 \%$

dengan:

$n \quad=$ banyaknya/jumlah data

$A_{t} \quad=$ data lapangan/observasi

$F_{t} \quad=$ data model simulasi

\section{A. METODE PENELITIAN}

\section{A.2. Metodologi Penelitian}

Penelitian ini menggunakan model simulasi VISSIM karena model simulasi ini merupakan perangkat lunak mikrokospik dengan metode stokastik yang mempunyai fasilitas kalibrasi yang membedakan dengan aplikasi model simulasi lain sehingga dapat menggambarkan perilaku pengemudi dan komposisi kendaraan. VISSIM mengandung model psycho-physical car following dan algoritma peraturan dasar untuk pergerakan kesamping (lateral behavior), yang menjadi karakteristik lalu lintas di indonesia yang berbeda dengan karakteristik lalu lintas dan perilaku pengemudi yang ada di negara-negara maju, disamping itu bagi peneliti pribadi alasan kemudahan (ketersediaan model) dalam penggunaan model menjadi pertimbangan dalam penggunaan model simulasi ini. Setelah mengkaji beberapa studi terdahulu mengenai kalibrasi model VISSIM pada jalinan, maka tahap selanjutnya :

1. Melakukan pengumpulan data yang meliputi:

a. Data inventarisasi jalinan;

b. Data lalu lintas meliputi: Kecepatan pada jalinan dan volume lalu lintas; 
2. Simulasi jaringan nyata ke dalam model VISSIM kondisi default

3. Kalibrasi parameter Behaviour melalui data pengamatan lapangan;

4. Kalibrasi parameter Behaviour melalui dari data lapangan

5. Kalibrasi parameter Behaviour dan perubahan lajur pada simulasi;

6. Perbandingan Hasil Kalibrasi;

7. Validasi Hasil Simulasi.

\section{B. Teknik Analisis Data}

Dalam penelitian ini metode kalibrasi menggunakan kalibrasi kapasitas dengan kandidat-kandidat parameter seperti proporsi sepeda motor, perilaku pengemudi dalam mengambil permulaan jalinan, perilaku pengendara sepeda motor dalam menyiap.

\section{ANALISIS DATA DAN PEMBAHASAN}

\section{A. ANALISA KONDISI EKSISTING}

\section{LINGKUP STUDI}

Penelitian ini membahas mengenai perbandingan hasil vissim eksisting dengan model padakawasan Pasar Wlingi Kabupaten Blitar.Cakupan wilayah studi merupakan beberapa ruas yang ada di kawasan Pasar Wlingi Kabupaten Blitar.Berikut ini Gambar V.1 Peta Kawasan Pasar Wlingi Kabupaten Blitar.
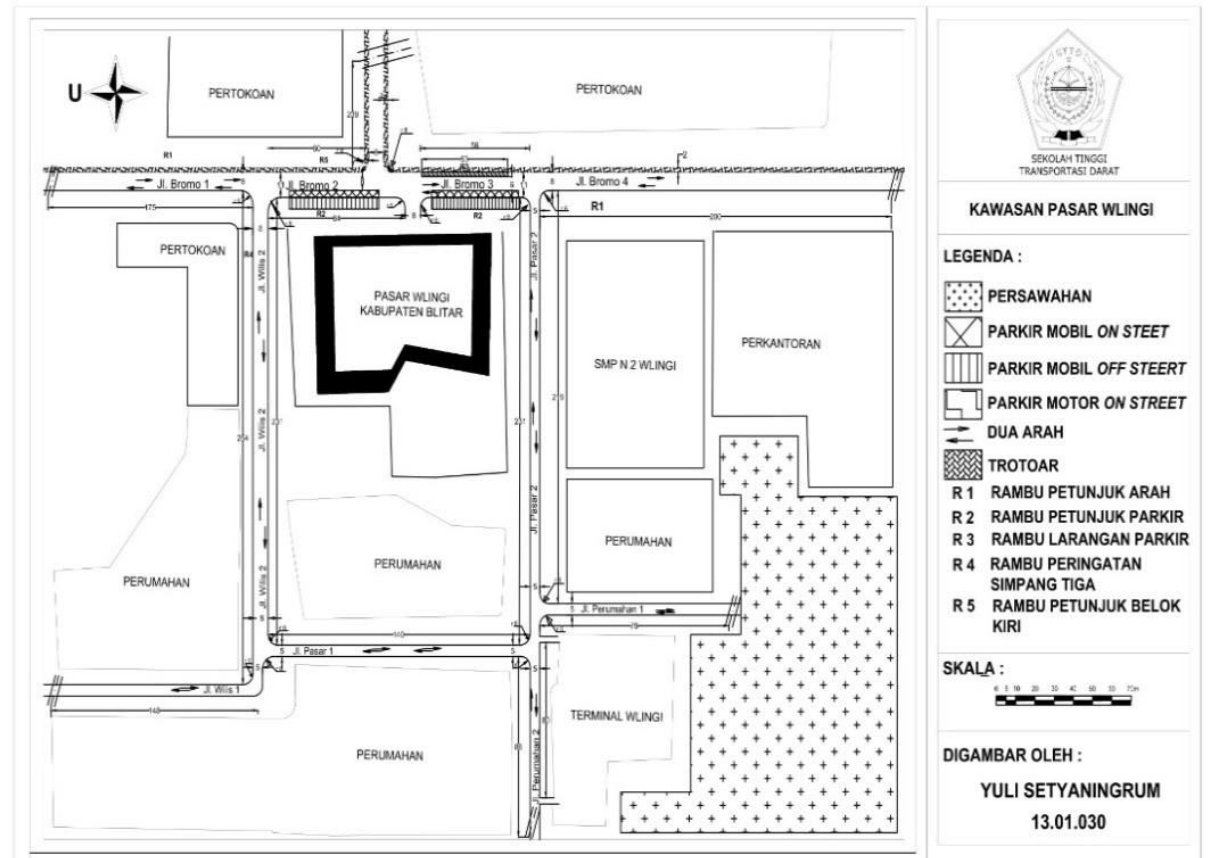

Sumber: Hasil Analisis, 2017

Gambar V.1 Peta Kawasan Pasar Wlingi Kabupaten Blitar 
Kawasan Pasar Wlingi Kabupaten Blitar merupakan pusat perdagangan dan jasa yang terletak pada jalur persimpangan yang tertumpu pada beberapa ruas jalan yang saling terhubung dan merupakan akses utama untuk keluar masuk kawasan pasar. Berikut merupakan peta kodefikasi jaringan jalan Pasar Wlingi Kabupaten Blitar ditunjukkan pada Gambar V.2di bawah ini.

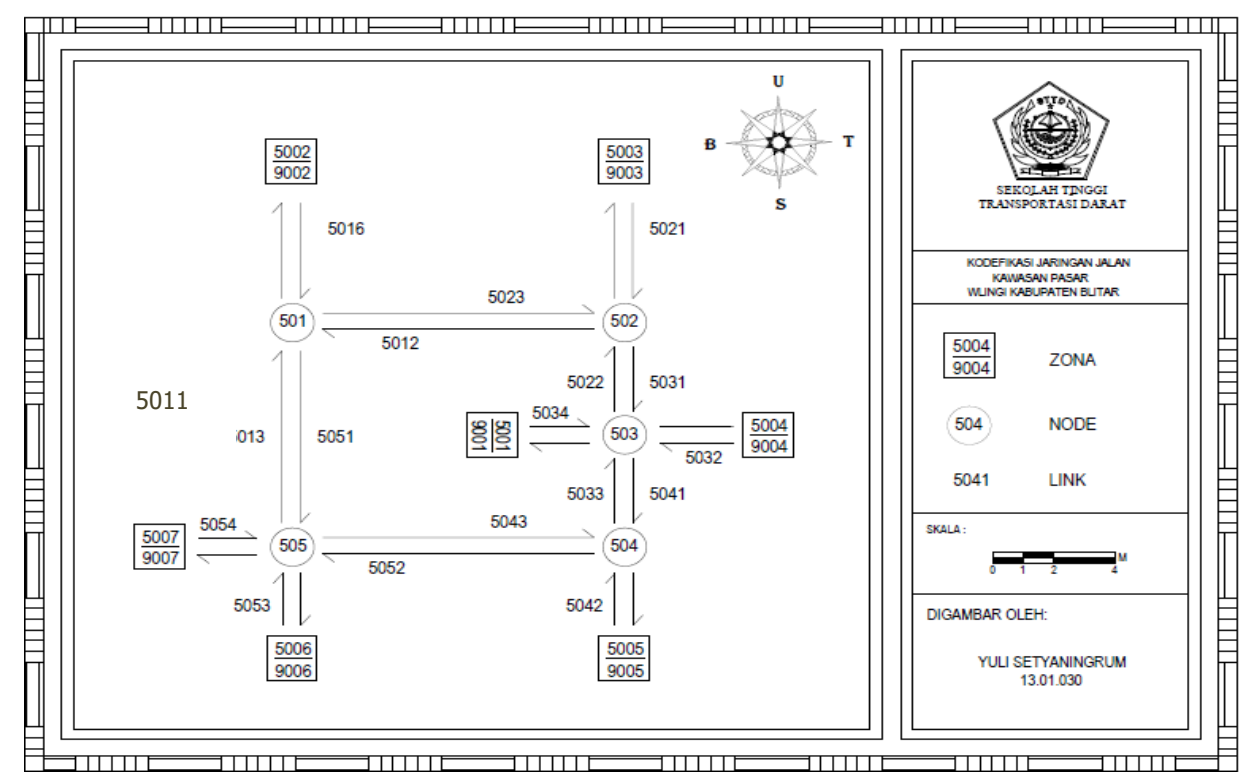

Sumber: Hasil Analisis, 2017

a. V/C Ratio

Perhitungan $V / C$ ratio di dapatkan dari perhitungan volume di bagi dengan kapasitas jalan, yang mana perhitungan $V / C$ ratio digunakan untuk mengetahui tingkat pelayanan pada ruas jalan. Perhitungan $V / C$ ratio lebih lanjut ditunjukkan pada Tabel V.5 di bawah ini.

Tabel V.5V/C Ratio Ruas Jalan Kawasan Pasar Wlingi

\begin{tabular}{|c|c|c|c|c|c|c|}
\hline \multirow{2}{*}{ No } & \multirow[b]{2}{*}{ Link } & \multirow[b]{2}{*}{ Nama Jalan } & \multicolumn{2}{|c|}{ Volume } & \multirow[b]{2}{*}{$\begin{array}{c}\text { Kapasita } \\
\text { s }\end{array}$} & \multirow[b]{2}{*}{ V/C Ratio } \\
\hline & & & $\begin{array}{l}\text { sm } \\
\text { p/j } \\
\text { am }\end{array}$ & $\begin{array}{c}\text { Kendar } \\
\text { aan } / \mathrm{Ja} \\
\text { m }\end{array}$ & & \\
\hline 1 & 5011 & Wilis 1 & 259 & 929 & 702,22 & 0,37 \\
\hline 2 & 5002 & Wilis 1 & 258 & 925 & 702,22 & 0,37 \\
\hline 3 & 5012 & Wilis 2 & 501 & 1797 & 1274,13 & 0,39 \\
\hline 4 & 5023 & Wilis 2 & 498 & 1787 & 1274,13 & 0,39 \\
\hline
\end{tabular}




\begin{tabular}{|c|c|c|c|c|c|c|}
\hline \multirow{2}{*}{ No } & \multirow[b]{2}{*}{ Link } & \multirow[b]{2}{*}{ Nama Jalan } & \multicolumn{2}{|c|}{ Volume } & \multirow[b]{2}{*}{$\begin{array}{c}\text { Kapasita } \\
\text { s }\end{array}$} & \multirow[b]{2}{*}{ V/C Ratio } \\
\hline & & & $\begin{array}{l}\text { sm } \\
p / j \\
\text { am }\end{array}$ & $\begin{array}{c}\text { Kendar } \\
\text { aan/Ja } \\
\text { m }\end{array}$ & & \\
\hline 5 & 5013 & Pasar 1 & 278 & 1005 & 702,22 & 0,40 \\
\hline 6 & 5051 & Pasar 1 & 281 & 1019 & 702,22 & 0,40 \\
\hline 7 & 5021 & Bromo 1 & 499 & 1637 & 1429,51 & 0,35 \\
\hline 8 & 5003 & Bromo 1 & 492 & 1636 & 1429,51 & 0,34 \\
\hline 9 & 5022 & Bromo 2 & 765 & 2531 & 1274,13 & 0,60 \\
\hline 10 & 5031 & Bromo 2 & 768 & 2564 & 1274,13 & 0,60 \\
\hline 11 & 5032 & Ijen & 538 & 1818 & 1274,13 & 0,42 \\
\hline 12 & 5004 & Ijen & 541 & 1823 & 1274,13 & 0,42 \\
\hline 13 & 5033 & Bromo 3 & 873 & 2889 & 1028,25 & 0,85 \\
\hline 14 & 5041 & Bromo 3 & 877 & 2928 & 1028,25 & 0,85 \\
\hline 15 & 5042 & Bromo 4 & 565 & 1887 & 1274,13 & 0,44 \\
\hline 16 & 5005 & Bromo 4 & 569 & 1918 & 1090,95 & 0,52 \\
\hline 17 & 5043 & Pasar 2 & 450 & 1598 & 702,22 & 0,64 \\
\hline 18 & 5052 & Pasar 2 & 450 & 1604 & 702,22 & 0,64 \\
\hline 19 & 5053 & Perumahan 1 & 187 & 676 & 702,22 & 0,27 \\
\hline 20 & 5006 & Perumahan 1 & 186 & 672 & 702,22 & 0,26 \\
\hline 21 & 5054 & Perumahan 2 & 257 & 924 & 702,22 & 0,37 \\
\hline 22 & 5007 & Perumahan 2 & 254 & 910 & 702,22 & 0,36 \\
\hline
\end{tabular}

Sumber : Laporan Umum Tim PKL Kabupaten Blitar 2016

Dari Tabel V.5 dapat diketahui bahwa ruas jalan yang memiliki V/C ratio tertinggi yakni Jalan Bromo 3 (link 5041 dan link 5033) dengan V/C ratio 0,85 Ruas jalan yang memiliki $V / C$ ratio terendah yakni Jalan Perumahan 1(link 5006) dengan $V / C$ ratio $0,26$. 
b. Kecepatan Ruas Jalan

Kecepatan ruas jalan pada Kawasan Pasar Wlingi Kabupaten Blitarditunjukkan pada Tabel V.6.

Tabel V.6

Kecepatan Ruas Jalan Kawasan Pasar Wlingi

\begin{tabular}{|c|c|c|c|}
\hline No & Link & Nama Jalan & $\begin{array}{c}\text { Kecepatan Per Arah } \\
(\mathrm{km} / \mathbf{j a m})\end{array}$ \\
\hline 1 & 5011 & Wilis 1 & 34 \\
\hline 2 & 5002 & Wilis 1 & 34 \\
\hline 3 & 5012 & Wilis 2 & 30 \\
\hline 4 & 5023 & Wilis 2 & 30 \\
\hline 5 & 5013 & Pasar 1 & 34 \\
\hline 6 & 5051 & Pasar 1 & 34 \\
\hline 7 & 5021 & Bromo 1 & 32 \\
\hline 8 & 5003 & Bromo 1 & 32 \\
\hline 9 & 5022 & Bromo 2 & 26,5 \\
\hline 10 & 5031 & Bromo 2 & 26,5 \\
\hline 11 & 5032 & Ijen & 30 \\
\hline 12 & 5004 & Ijen & 30 \\
\hline 13 & 5033 & Bromo 3 & 21,02 \\
\hline 14 & 5041 & Bromo 3 & 21,02 \\
\hline 15 & 5042 & Bromo 4 & 30 \\
\hline 16 & 5005 & Bromo 4 & 30 \\
\hline 17 & 5043 & Pasar 2 & 28,85 \\
\hline 18 & 5052 & Pasar 2 & 28,85 \\
\hline 19 & 5053 & Perumahan 1 & 35 \\
\hline 20 & 5006 & Perumahan 1 & 35 \\
\hline
\end{tabular}




\begin{tabular}{|c|c|l|c|}
\hline No & Link & \multicolumn{1}{|c|}{ Nama Jalan } & $\begin{array}{c}\text { Kecepatan Per Arah } \\
\text { (km/jam) }\end{array}$ \\
\hline 21 & 5054 & Perumahan 2 & 34,21 \\
\hline 22 & 5007 & Perumahan 2 & 34,21 \\
\hline
\end{tabular}

Sumber: Laporan Umum Tim PKL Kabupaten Blitar 2016

Berdasarkan Tabel V.6 dapat diketahui bahwa ruas jalan yang memiliki kecepatan tertinggi adalah Jalan Perumahan 1(link 5053 dan link 5006) dengan kecepatan sebesar $35 \mathrm{~km} / \mathrm{jam}$. Sedangkan kecepatan terendah yakni terdapat pada Jalan Bromo 3 (link 5041 dan link 5033) dengan kecepatan sebesar 21,02 $\mathrm{km} / \mathrm{jam}$.

\section{B. IDENTIFIKASI PERMASALAHAN}

1. Kinerja Lalu Lintas Pada Kondisi Sekarang (Eksisting) 2016

Dari hasil analisis data pada proses pembebanan ruas jalan dan persimpangan, dapat diketahui bahwa kinerja lalu lintas pada Kawasan Pasar Wlingi Kabupaten Blitar telah menunjukkan adanya permasalahan.Permasalahan ini terjadi pada saat jam sibuk dan diruas jalan yang mempunyai aktifitas kegiatan tinggi seperti ruas jalan yang berada disekitar daerah pertokoan. Berikut Tabel V.39 merupakan hasil kinerja ruas jalan pada Kawasan Pasar Wlingi.

Tabel V.39 Unjuk Kinerja Ruas Jalan Pada Kawasan Pasar Wlingi

\begin{tabular}{|c|c|l|c|c|c|c|c|}
\hline \multirow{2}{*}{ No } & \multirow{2}{*}{ Link } & \multirow{2}{*}{$\begin{array}{l}\text { Nama } \\
\text { Jalan }\end{array}$} & smp/jam & $\begin{array}{c}|c| \\
\text { Kendaraan/ } \\
\text { Jam }\end{array}$ & $\begin{array}{c}\text { Kapasit } \\
\text { as }\end{array}$ & $\begin{array}{c}\text { V/C } \\
\text { Ratio }\end{array}$ & $\begin{array}{c}\text { Tingkat } \\
\text { Pelayanan }\end{array}$ \\
\hline 1 & 5011 & Wilis 1 & 259 & 929 & 702,22 & 0,37 & B \\
\hline 2 & 5002 & Wilis 1 & 258 & 925 & 702,22 & 0,37 & B \\
\hline 3 & 5012 & Wilis 2 & 501 & 1797 & 1274,13 & 0,39 & B \\
\hline 4 & 5023 & Wilis 2 & 498 & 1787 & 1274,13 & 0,39 & B \\
\hline 5 & 5013 & Pasar 1 & 278 & 1005 & 702,22 & 0,40 & B \\
\hline 6 & 5051 & Pasar 1 & 281 & 1019 & 702,22 & 0,40 & B \\
\hline
\end{tabular}




\begin{tabular}{|c|c|c|c|c|c|c|c|}
\hline \multirow[b]{2}{*}{ No } & \multirow[b]{2}{*}{ Link } & \multirow[b]{2}{*}{$\begin{array}{l}\text { Nama } \\
\text { Jalan }\end{array}$} & \multicolumn{2}{|c|}{ Volume } & \multirow[b]{2}{*}{$\begin{array}{c}\text { Kapasit } \\
\text { as }\end{array}$} & \multirow[b]{2}{*}{$\begin{array}{c}\text { V/C } \\
\text { Ratio }\end{array}$} & \multirow[b]{2}{*}{$\begin{array}{c}\text { Tingkat } \\
\text { Pelayanan }\end{array}$} \\
\hline & & & smp/jam & $\begin{array}{c}\text { Kendaraan/ } \\
\text { Jam }\end{array}$ & & & \\
\hline 7 & 5021 & Bromo 1 & 499 & 1637 & 1429,51 & 0,35 & B \\
\hline 8 & 5003 & Bromo 1 & 492 & 1636 & 1429,51 & 0,34 & B \\
\hline 9 & 5022 & Bromo 2 & 765 & 2531 & 1274,13 & 0,60 & $\mathrm{C}$ \\
\hline 10 & 5031 & Bromo 2 & 768 & 2564 & 1274,13 & 0,60 & $\mathrm{C}$ \\
\hline 11 & 5032 & Ijen & 538 & 1818 & 1274,13 & 0,42 & B \\
\hline 12 & 5004 & Ijen & 541 & 1823 & 1274,13 & 0,53 & $\mathrm{C}$ \\
\hline 13 & 5033 & Bromo 3 & 873 & 2889 & 1028,25 & 0,85 & $\mathrm{D}$ \\
\hline 14 & 5041 & Bromo 3 & 877 & 2928 & 1028,25 & 0,85 & $\mathrm{D}$ \\
\hline 15 & 5042 & Bromo 4 & 565 & 1887 & 1274,13 & 0,44 & B \\
\hline 16 & 5005 & Bromo 4 & 569 & 1918 & 1274,13 & 0,52 & $\mathrm{C}$ \\
\hline 17 & 5043 & Pasar 2 & 450 & 1598 & 702,22 & 0,64 & $\mathrm{C}$ \\
\hline 18 & 5052 & Pasar 2 & 450 & 1604 & 702,22 & 0,64 & $\mathrm{C}$ \\
\hline 19 & 5053 & $\begin{array}{l}\text { Perumah } \\
\text { an } 1\end{array}$ & 187 & 676 & 702,22 & 0,27 & B \\
\hline 20 & 5006 & $\begin{array}{l}\text { Perumah } \\
\text { an } 1\end{array}$ & 186 & 672 & 702,22 & 0,26 & $\mathrm{~B}$ \\
\hline 21 & 5054 & $\begin{array}{l}\text { Perumah } \\
\text { an } 2\end{array}$ & 257 & 924 & 702,22 & 0,37 & B \\
\hline 22 & 5007 & $\begin{array}{l}\text { Perumah } \\
\text { an } 2\end{array}$ & 254 & 910 & 702,22 & 0,36 & B \\
\hline
\end{tabular}

2. Kinerja Jaringan Jalan Pada Kondisi Sekarang (Eksisting) 2016 Secara makro dapat diketahui bahwa kinerja lalu lintas pada jaringan jalan Kawasan Pasar Wlingi terdapat permasalahan.Berdasarkan hasil pembebanan yang dilakukan dengan software Vissim pada jaringan jalan di Kawasan Pasar Wlingi menunjukkan perlu dilakukannya penanganan.Kinerja jaringan jalan eksisting ditunjukkan pada Tabel V.40 berikut ini. 
Tabel V.40 Kinerja Jaringan Jalan Kondisi Sekarang (Eksisting)

\begin{tabular}{|c|l|c|}
\hline No & \multicolumn{1}{|c|}{ Parameter } & Total \\
\hline 1 & Total Waktu Perjalanan (detik) & 1876,51 \\
\hline 2 & Total Jarak Perjalanan (m) & $5.111,76$ \\
\hline 3 & Waktu Tundaan Rata-Rata (detik) & 33,45 \\
\hline 4 & Kecepatan Rata-Rata (Km/Jam) & 29,42 \\
\hline
\end{tabular}

Dari Tabel V.40 diatas, maka dapat diketahui kondisi transportasi pada Kawasan Pasar Wlingi menunjukkan bahwa kinerja jaringan jaringan jalan kondisi pada saat sekarang (eksisiting) memiliki tundaan rata-rata 33,45 detik dan kecepatan perjalanan 29,42 km/jam. Total jarak perjalanan $5.111,76 \mathrm{~km}$, total waktu perjalanan $1.876,51$ detik.

\section{Kalibrasi VISSIM}

1. Metode pengambilan data di lapangan tiap parameter

VISSIM MERUPAKAN ALAT YANG DIGUNAKAN UNTUK MELAKUKAN SIMULASI TRANSPORTASI DALAM BERBAGAI MACAM SIMULASI. MODEL INI TENTUNYA HARUS DISESUAIKAN DENGAN KONDISI LAPANGAN AGAR MODEL DAPAT MEREPRESENTASIKAN KONDISI SEBENARNYA. SEDANGKAN PARAMETER-PARAMETER VISSIM ANTARA LAIN DIBAGI MENJADI TIGA, YAITU TERKAIT DENGAN CAR FOLLOWING, LANE CHANGING DAN LATERAL BEHAVIOUR. ADAPUN HASIL DARI PENGUMPULAN DATA PARAMETER YANG DILAKUKAN DENGAN METODE PENGAMATAN LAPANGAN DAPAT DILIHAT PADA TABEL BERIKUT:

Tabel 1. Hasil Pengamatan Lapangan Kalibrasi Parameter Model VISSIM

\begin{tabular}{||l|c|c||}
\hline \multicolumn{1}{|||}{ PARAMETER } & DEFAULT VALUE & CALIBRATED VALUE \\
\hline Driving behaviour parameters & & \\
\hline Look Ahead Distance (m) & & \\
\hline Minimum & 0 & 225 \\
\hline Maximum & 250 & \\
\hline
\end{tabular}




\begin{tabular}{|c|c|c|}
\hline PARAMETER & DEFAULT VALUE & CALIBRATED VALUE \\
\hline Number of observed vehicles & 4 & 8 \\
\hline \multicolumn{3}{|l|}{ Look Back Distance (m) } \\
\hline Minimum & 0 & 15 \\
\hline Maximum & 150 & 100 \\
\hline \multicolumn{3}{|l|}{ Lane change } \\
\hline Waiting time before diffusion (s) & 60 & 180 \\
\hline Minimum headway $(\mathrm{m})$ & 0.5 & 0.3 \\
\hline \multicolumn{3}{|l|}{ Lateral behaviour } \\
\hline Desired position at free flow & Middle & Any \\
\hline Diamond shaped queuing & No & Yes \\
\hline Consider next turning direction & No & Yes \\
\hline Overtake on same lane & No & On left and right \\
\hline \multicolumn{3}{|c|}{ Min. lateral distance at $0 \& 50 \mathrm{kmph}(\mathrm{m})$} \\
\hline Motorcycle & 1 dan 1 & 0.1 dan 0.3 \\
\hline Car & 1 dan 1 & 0.2 dan 1.0 \\
\hline Truk & 1 dan 2 & 0.5 dan 1.5 \\
\hline
\end{tabular}

Sedangkan untuk langkah kedua dengan melakukan proses kalibrasi parameter yaitu untuk mendapat parameter dari parameter Wiedemann 1974 seperti : Average Standstill Distance, Additive part of desired safety distance dan Multiplicative part of desired safety distance. Dengan menggunakan metode Trial Error, yaitu mensimulasikan set nilai parameter dengan beragam nilai sheet random dan membandingkan dengan kondisi lapangan. Hasil Evaluasi jaringan dilakukan untuk menguji apakah set parameter default menyediakan hasil yang dapat diterima secara statistik. Pengulangan sebanyak 5 pengulangan simulasi VISSIM dengan data set parameter coba-coba. Pengujian data tersebut dapat dilihat pada perhitungan dibawah ini. 
Tabel 2.

Evaluasi Jaringan terhadap Parameter Car Following dengan Metode Trial Error

\begin{tabular}{|c|c|c|c|c|c|c|}
\hline \multirow{2}{*}{$\begin{array}{c}\text { BASE DATA DRIVING } \\
\text { BEHAVIOUR PARAMETER } \\
\text { SETS }\end{array}$} & \multirow{2}{*}{ DEFAULT } & \multicolumn{5}{|c|}{ SIMULASI } \\
\hline & & 1 & 2 & 3 & 4 & 5 \\
\hline Average Standstill Distance & 2 & 1.45 & 1.35 & 1.15 & 1.25 & 1.45 \\
\hline $\begin{array}{l}\text { Additive part of desired safety } \\
\text { distance }\end{array}$ & 3 & 1.25 & 0.25 & 2.25 & 1.25 & 0.25 \\
\hline $\begin{array}{l}\text { Multiplicative part of desired } \\
\text { safety distance }\end{array}$ & 3 & 2.35 & 0.35 & 0.35 & 0.35 & 1.35 \\
\hline Evaluation & & & & & & \\
\hline Average Simulated & 101 & 115 & 149 & 190 & 174 & 188 \\
\hline Average Observed & 158 & 158 & 158 & 158 & 158 & 158 \\
\hline$\%$ error & 36.108 & 27.182 & 5.320 & -20.656 & -10.417 & -19.118 \\
\hline RMSE & 74.601 & 28.539 & 41.215 & 47.961 & 44.498 & 45.705 \\
\hline T-Test & 0.023 & 0.089 & 0.766 & 0.286 & 0.575 & 0.313 \\
\hline
\end{tabular}

\section{DAFTAR PUSTAKA}

Undang Undang Nomor 22 Tahun 2009 Tentang Lalulintas dan Angkutan Jalan, 2009, Jakarta.

Sugiyono, (2007), "Statistik Untuk Penelitian”, Edisi kedua belas, Alfabeta, Bandung.

Direktorat Jenderal Bina Marga Departemen Pekerjaan Umum, Manual Kapasitas Jalan Indonesia, 1997, Jakarta.

Wright, Paul H., Ashford, Norman J., Transportation Engineering : Planning and Design, Third Edition, 1989, John Wiley and Sons Inc., Canada

David A Hensher, Kenneth J Button. (2000). Handbook of Transport Modelling, Elsevier Science Ltd. United Kingdom.

F D Hobbs. (1979). Traffic Planning And Engineering, second edition, Pergamon Press, England.

Ortuzar J D, and Wilumsen L G.(1994). Modelling Transport, second edition, John Wiley \& Sons, Chichester, England. 
